\title{
ESCCAP-wormbestrijding bij hond en kat
}

\author{
Herziene 6e druk Richtlijn 1
}

\author{
R. Nijsse, E. Claerebout, M. Leistra, P. Overgaauw \\ edwin.claerebout@ugent.be
}

\begin{abstract}
Dit jaar verscheen een nieuwe, herziene druk van de meest gedownloade richtlijn van de ESCCAP (European Counsel Companion Animal Parasites) over worminfecties bij hond en kat (www.esccap.eu). Een update van een richtlijn wordt door een commissie van drie ESCCAP-leden voorbereid waarna alle leden uit de verschillende Europese landen hun commentaar op de tekst mogen leveren. Op basis van deze feedback wordt een definitieve versie opgemaakt, die daarna in de verschillende landstalen vertaald wordt. Deze procedure neemt snel langer dan een jaar in beslag.
\end{abstract}

\section{Wat is nieuw?}

Hierna worden de meest opvallende veranderingen besproken. Het begint met een aanpassing van de indeling per groep van relevante intestinale en nietintestinale wormen die praktischer van opbouw en volgorde is dan in de vorige druk.

$\mathrm{Na}$ de spoelwormen worden de lintwormen, Dirofilaria spp., Angiostrongylus vasorum, haakwormen en zweepwormen besproken. De aanwezigheid van Echinococcus granulosus (kleine hondenlintworm), E. multilocularis (vossenlintworm), Dirofilaria immitis (hartworm) en D. repens (subcutane worm) op de kaart van Europa is weer geactualiseerd en van alle parasieten zijn de levenscycli nu grafisch weergegeven. Deze cycli zijn ook allemaal, individueel van de ESCCAP-website te downloaden voor eigen gebruik (www.esccap.org) (Figuur 1).

Vanzelfsprekend zijn sommige wormen belangrijker dan andere, afhankelijk van de prevalentie, het ziekteverwekkend vermogen bij de gastheer, eventueel potentieel zoönotisch karakter of een combinatie van deze factoren.

\section{Informatieve tabellen}

Daarnaast is meer gedetailleerde informatie opgenomen in een groot aantal tabellen. Dit betreft gegevens over de verschillende wormsoorten zoals (pre) patentperiode, infectieuze stadia, de besmettingsweg, verspreiding in Europa en de eindgastheer. Ook geven de tabellen een overzicht van de risicofactoren voor het oplopen van worminfecties bij hond en kat zoals levensstadium (jonge dieren, lactatie, zwerfgeschiedenis), gezondheid (aanwezigheid van vlooien of luizen), omgeving (kennels, buitenshuis), voeding (predatie knaagdieren, vogels, amfibieën, reptielen, slakken of rauw vlees), locatie of reizen. De laatste tabellen geven informatie over de klinische symptomen, te onderzoeken materiaal voor diagnostiek en diagnostische technieken.

\section{Stappenplan ontworming}

Veel tijd is besteed aan de ontwikkeling van een logisch en overzichtelijk stappenplan voor de adviezen met betrekking tot het hoe vaak en wanneer ontwormen van honden en katten. In de nieuwe richtlijn is deze nu uitgesplitst voor hond (4 risicogroepen) en kat (2 risicogroepen).

Het toekennen van een bepaalde risicogroep en bijbehorende ontwormingsfrequentie is afhankelijk van de factoren zoals leeftijd, wel of niet buiten komen, het eten van prooidieren, slakken of rauw vlees en het leven in vossenlintworm-endemisch gebied. Daarbij heeft de in Benelux al enkele jaren gebruikte beslisboom als voorbeeld gediend.

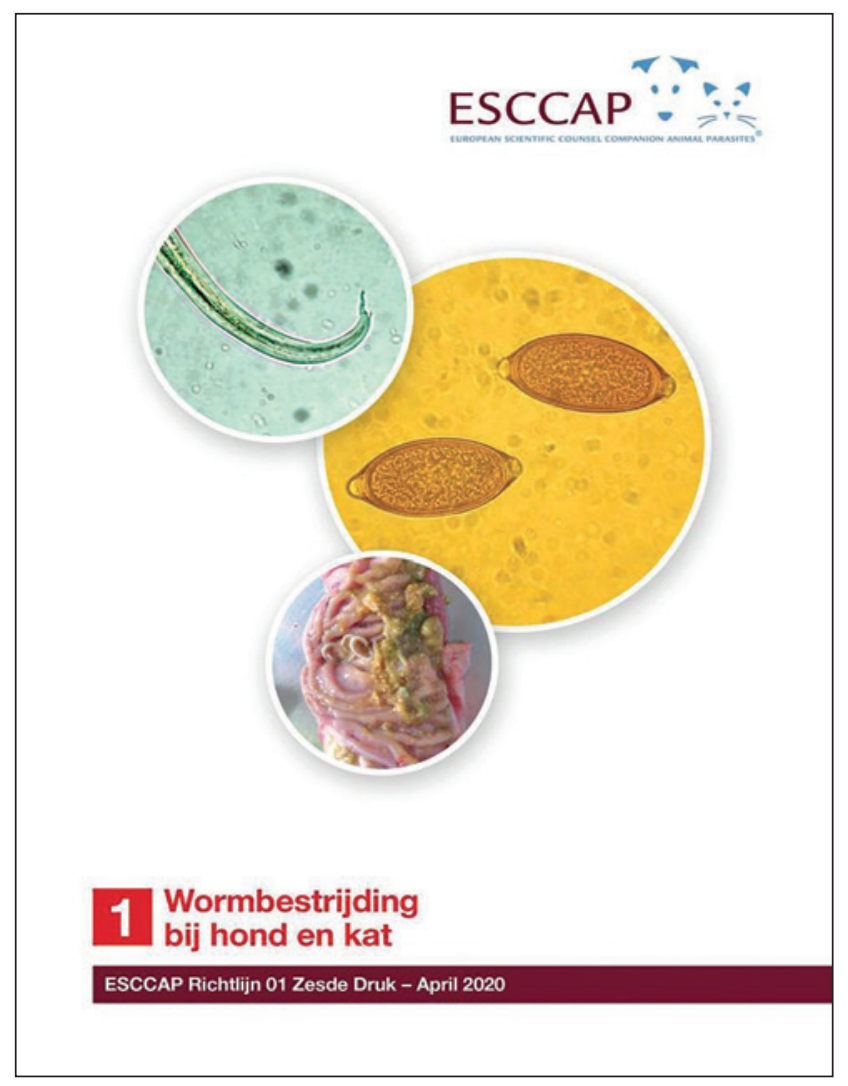

Figuur 1. De nieuwe ESCCAP Richtlijn 1 


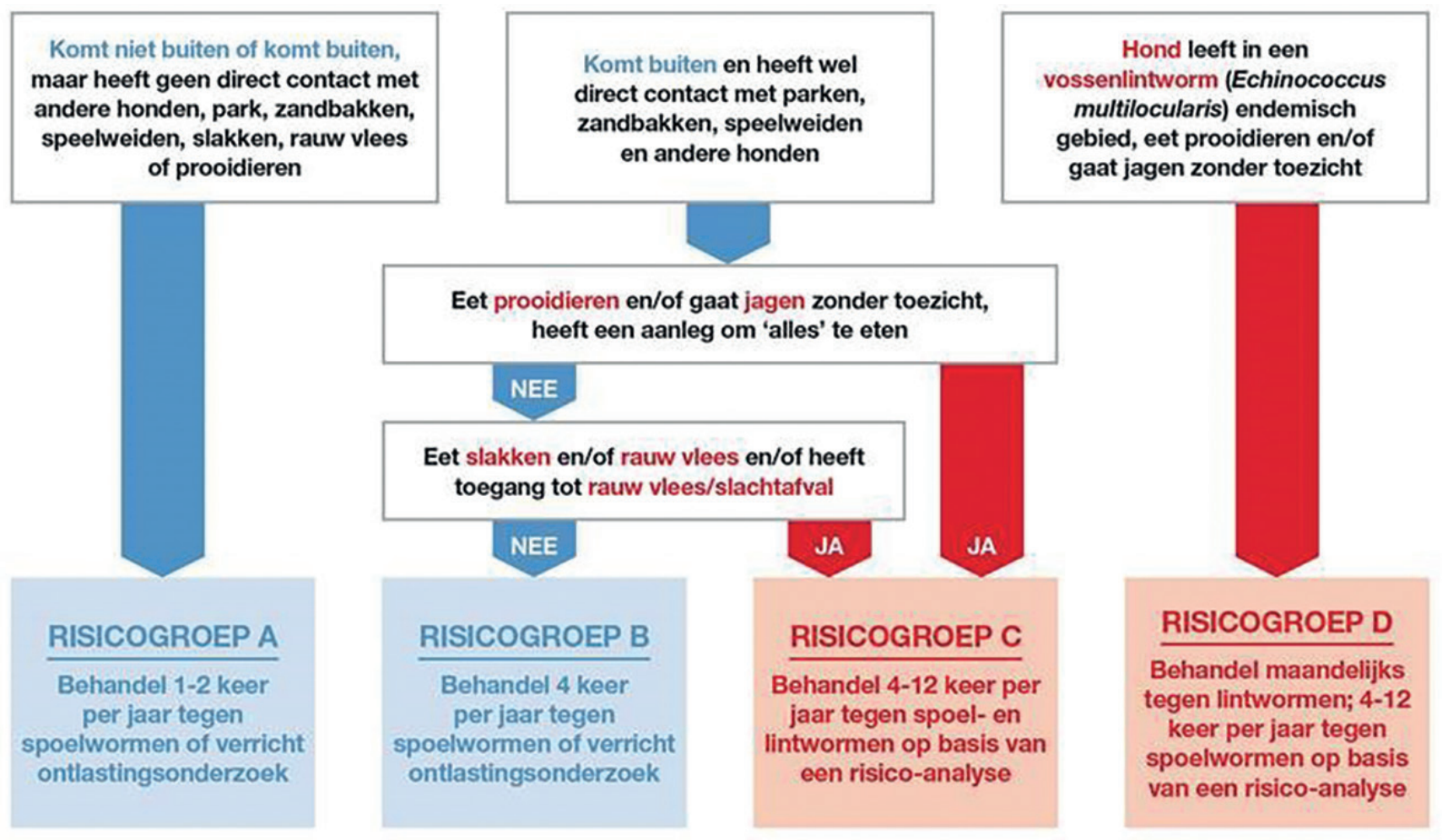

Figuur 2. Beslisboom voor de ontworming van de hond.
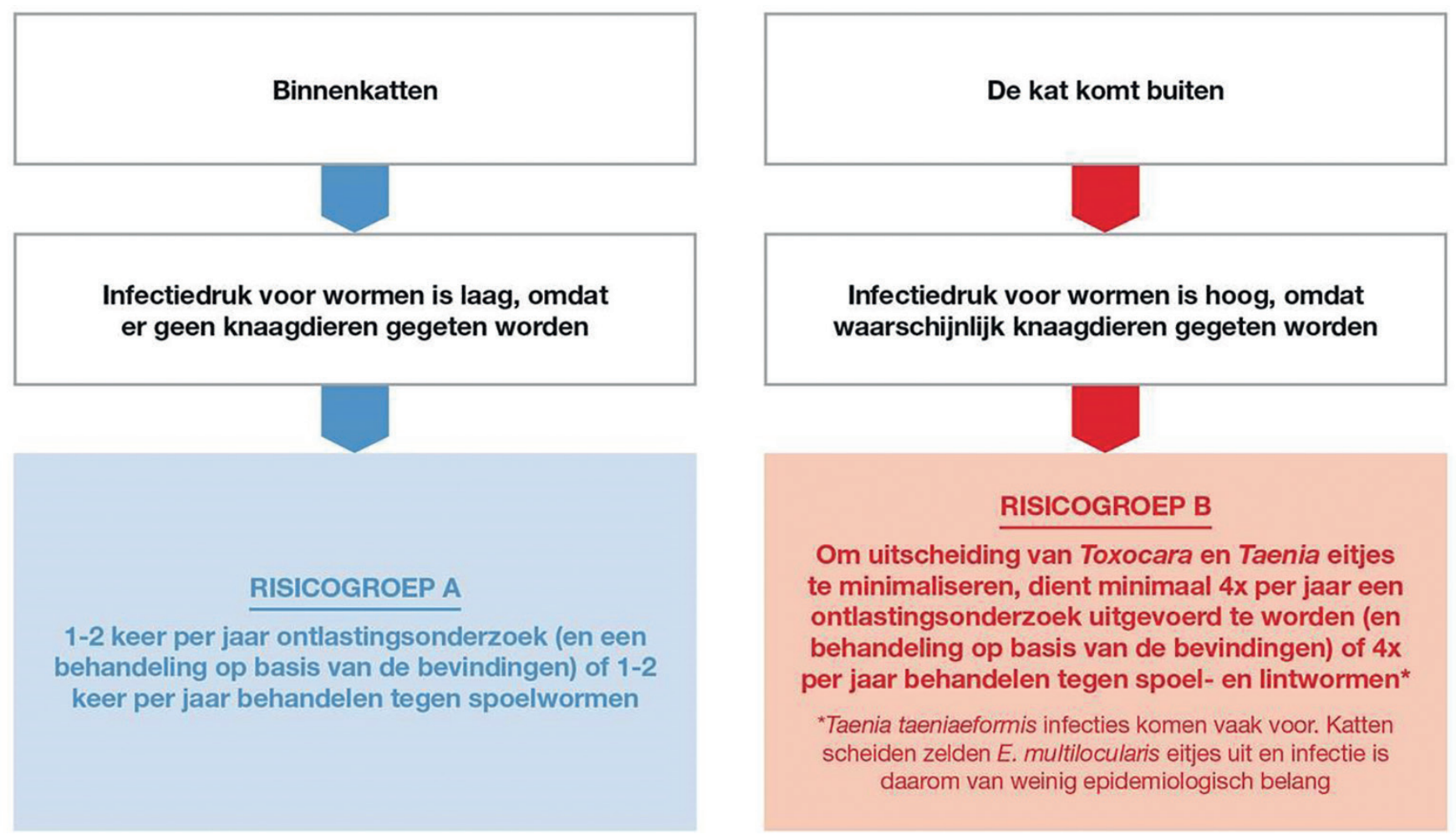

Figuur 3. Beslisboom voor de ontworming van de kat. 
Het basisadvies blijft gehandhaafd om bij voorkeur op basis van de resultaten van een regelmatig uitgevoerd fecesonderzoek te ontwormen en ontworming niet routinematig toe te passen. Als er wel routinematig wordt ontwormd kan de frequentie hiervan verlopen volgens de beslisboom.

Vanzelfsprekend beschermt dit niet tegen patente infecties die tussendoor ontstaan. Er wordt duidelijk geadviseerd om ontwormen alleen te laten plaatsvinden op advies van de dierenarts. De reden hiervoor is dat deze het beste kan inschatten welke ontwormingsfrequentie bij een bepaald dier past en geadviseerd dient te worden (Figuur 2 en 3 ).

\section{Wisselende interpretatie van sommige adviezen}

Toch zijn er door het consensusmodel met input van vele landen in de richtlijn, adviezen vermeld die in de Benelux niet of minder gangbaar zijn. Bijvoorbeeld het advies om honden en katten die in huis leven met kinderen jonger dan vijf jaar of met personen met een verminderde afweer routinematig maandelijks te ontwormen, afhankelijk van een risicoanalyse of op basis van de bevindingen van fecesonderzoek. Dit heeft te maken met de preventie van patente Toxocara-infecties bij hond/kat in het kader van de volksgezondheid. Er wordt echter de suggestie gewekt dat honden en katten een groter risico lopen op een (patente) worminfectie als ze in dergelijke huishoudens wonen. Dat is natuurlijk niet het geval en andersom is het ook niet zo dat het maandelijks ontwormen de kinderen gaat beschermen tegen Toxocara-infectie. Deze zoönose wordt namelijk niet opgelopen door direct contact met hond of kat en zelfs niet door onverhoopt contact met de "verse" ontlasting van besmette dieren. De eitjes hebben namelijk minimaal enkele weken nodig om te embryoneren en infectieus te worden. Het risico van het opnemen van Toxocara-eitjes door vachtcontact is door gedegen onderzoek in Nederland en Ierland ook ontkracht. Dit kan hoogstens een rol spelen bij direct contact met zwerfhonden en met name de pups hiervan. Alleen wanneer uit de risicoanalyse blijkt dat Toxocara-besmetting aanwezig kan zijn en de aanwezige dieren in de tuin defeceren waarin de kinderen spelen en de ontlasting niet wordt verwijderd (risicoanalyse), is een dergelijk advies zinvol.

Als er een Echinococcus-lintworm aanwezig is, dan is besmetting door vachtcontact wél mogelijk omdat deze eitjes direct infectieus zijn. Niet elk anthelminthicum is echter werkzaam tegen lintwormen.

Kinderen worden vooral besmet door grondcontact waarin zich geëmbryoneerde Toxocara-eitjes bevinden. Parken, speelweiden en niet-afgesloten zandbakken worden hierop wereldwijd positief bevonden.

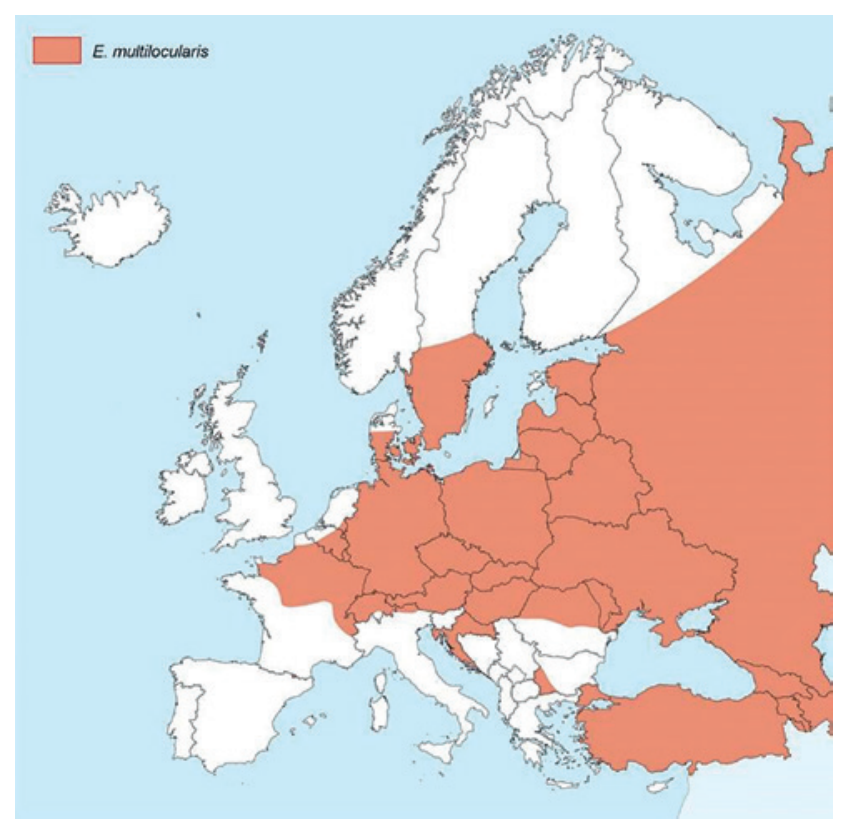

Figuur 4. Prevalentie van de vossenlintworm in Europa.

Een ander nieuw advies dat ook afwijkt van het advies in de Benelux, is om hond en kat routinematig te ontwormen tegen Taenia-lintwormen. De ESCCAPontwormingsadviezen zijn van oorsprong bedoeld om gastheren te beschermen tegen pathogene infecties zoals de Franse hartworm en/of tegen zoönotische infecties zoals Toxocara spp. of Echinococcus spp. Taenia-lintwormen zijn noch pathogeen voor hond of kat, noch voor de mens en komen bovendien zelden voor. Sporadisch wordt er gemeld dat grote aantallen darmobstipatie kunnen veroorzaken, maar dit is geen reden om standaard tegen lintworm te ontwormen. Pas als Taenia-lintwormen worden waargenomen of in een gebied dat enzoötisch is voor de vossenlintworm, is ontworming zinvol (Figuur 4).

In de Engelse versie wordt vermeld dat drachtige teven vanaf de veertigste dag van de dracht ook preventief ontwormd kunnen worden. Naast het feit dat hiervoor geen producten zijn geregistreerd in de Benelux, wordt dit ook niet door ESCCAP Benelux geadviseerd omdat het behandelen duur en bewerkelijk is, er geen sluitend wetenschappelijk bewijs is en pups tot het spenen iedere twee weken ontwormd dienen te worden tegen Toxocara canis.

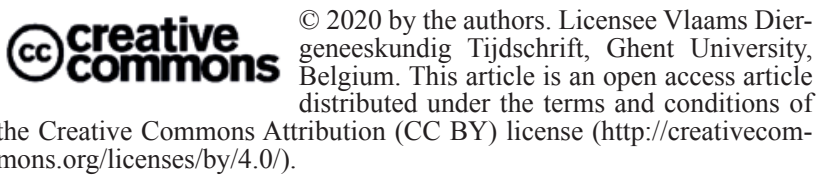

